\title{
Diversion following rectal cancer surgery
}

\author{
Wasantha Wijenayake \\ Department of Surgery, Faculty of Medicine, KDU, Sri Lanka
}

Keywords: Stoma; ileostomy; colostomy; anastomotic leak; rectal cancer; proximal diversion; defunctioning stoma; percutaneous ileostomy; ghost ileostomy

\begin{abstract}
Rectal cancer surgery is moving from organ sacrificing abdominoperineal resection (APR) to organ-preserving anterior resection (AR). Neoadjuvant chemoradiation, low anterior resection and coloanal anastomosis play a major role in this context. Anastomotic leakage (AL) is the most feared complication of these procedures. Therefore, much importance is given to proximal diversions to protect anastomosis. This review has critically analysed the indications, various methods available, challenges, complications, benefits and patient selection for proximal diversions.
\end{abstract}

\section{Introduction}

Rectal cancer surgery has developed from organ sacrificing abdominoperineal resection to organ-preserving procedures with the introduction of Total Mesorectal Excision (TME), neoadjuvant chemoradiation and Trans-anal TME (TaTME). As a result of this, more rectal tumours in the distal rectum end up with restored continuity of the bowel with even lower anastomosis in the pelvis.

An anastomotic leak (AL) is the most dreaded complication for a surgeon as it can lead to the death of a patient. Introduction of proximal diversion of the faecal stream by various methods is considered protective of AL. However, this is not without debate on exact indications, methods of diversion, the morbidity associated with diversion and issues on the reversal of proximal diversion as well. This review aims to ascertain/assess the available evidence on these issues to find answers for them.

Protection of the anastomotic site is achieved by the temporary diversion of the faecal stream before reaching it and bringing it out as a stoma through the anterior abdominal

Correspondence: Wasantha Wijenayake

E-mail: wasanthaw12@msn.com

Received: 20-02-2019 Accepted: 13-07-2019

(iD http://orcid.org/0000-0001-6063-9840

DOI: http://doi.org/10.4038/sljs.v37i2.8624

The Sri Lanka Journal of Surgery 2019; 37(2): 9-11 wall. Defunctioning or diverting stoma is created to minimize the impact of a subsequent anastomotic leak.

The International Study Group of Rectal Cancer (ISREC) have defined an anastomotic leak(AL) as 'a communication between the intra- and extra-luminal compartments owing to a defect of the integrity of the intestinal wall at the anastomotic site'[1]. Demonstration of a pelvic abscess in the vicinity of an anastomosis, without demonstrable communication with the bowel lumen, is also considered as originated from a leak. This definition does not include microscopic leaks which are not clinically evident in most of the time.

\section{Diversion or no diversion}

Whether to divert patients undergoing rectal cancer surgery or not was debated but has come up with mixed conclusions. A meta-analysis of four randomized clinical trials and 21 nonrandomized trials including 11429 patients by Tan, W.S et al[2] concluded as; a defunctioning stoma would reduce the clinical anastomotic leak rate and reoperation rates. Further, in the same analysis, they found a statistically significant reduction of mortality among patients with a stoma in the nonrandomized group. Same conclusions were made on anastomotic leaks and reoperations by another meta-analysis of 11 studies by Sheng-Wen Wu et al[3] as well.

A contrary report was published 2017 by Yuchen Wu et al [4] in Nature conclude 'diverting stoma does not delay or reduce the AL but it reduces the recovery time of non-severe AL'. Further, they did not detect a positive impact on the occurrence or recovery of sever AL and its manifestation on distant or local recurrence rates or relapse-free survival as well. By this publication, Yuchen Wu et al have challenged the popular belief of reduction of consequences of AL by a diverting stoma.

Minimal invasive methods have established its place in colorectal surgery and proven to have technical advantages in rectal cancer surgery $[5,6,7]$. Peter Ihnat et al[8] concluded in a publication in 2016 that diverting ileostomy does protect the anastomosis following laparoscopic rectal cancer surgery but at a high price in terms of ileostomy related complications and 
morbidity.

Considering all the evidence in front of us it is fair to conclude proximal diversion after rectal cancer surgery should be individualized.

\section{What is the method to divert?}

A proximal diverting loop ileostomy is the most popular method of diversion owing to advantages over colostomy [9]. However meta-analysis on 5 randomized trials has failed to appreciate any significant advantage between these two methods; diverting ileostomy or colostomy [10]. Even though fewer incidents associated with ileostomy prolapse is seen as an advantage over colostomy in this meta-analysis, some may consider this as helpful in a reversal of stoma. Another randomized trial looked at the more significant complication of intestinal obstruction and concluded that colostomy is associated with less incidence of obstruction [11].

With all the above evidence and considering that $\mathrm{AL}$ rate following TME and LAR is around $7.5-10 \%[12,13]$; we may be creating stomas in $90 \%$ or more patients subjecting them to stoma related complications and morbidity without a real advantage. Should we create diverting stoma at all or is there a less invasive and convenient way to mature a stoma if the need arises? There are two methods described and practised i.e. Temporary percutaneous ileostomy(TPI)[14, 15] and Ghost ileostomy $(\mathrm{GI})[16,17]$.

Patients with TPI will have a feeding jejunostomy tube inserted into the proximal limb of an ileal loop and will obliterate the lumen by inflating the balloon of the tube. Other end of the tube will be delivered out through the anterior abdominal wall[15]. Advantage of this method is the ability to reverse it without another surgery on an average of 9 days against 106 days on average for a conventional loop ileostomy(CLI) availing the CLI related complications [14].

GI is the least invasive method to mature an ileostomy in the event an AL is suspected. This will mark and facilitate the site to create an ileostomy in the unfortunate occurrence of an AL[16,17]. Therefore, GI will prevent all complications related to CLI and minimize the morbidity as well.

\section{Challenges, Issues and Limitations}

Diverting stomas are also not without complications and there is a certain amount of reduction of quality of life simply due to stoma related complications and morbidity in relation to skin excoriation, stoma leakage, stoma obstruction and retraction [18]. However, when it comes to other patients who would end up having LAR, decision making can be governed by various other factors like preceding chemoradiation, general fitness, and co-morbidities. Besides, we have to take into consideration the possibility to reverse the stoma as well and the consequences of stoma reversal. Some of the temporary stomas will become permanent due to the simple fact they never get reversed [19]. Other stomas will not be reversed because patients were given preoperative chemoradiation [20] or started on adjuvant chemotherapy. However the evidence support that reversal could be carried out safely while patients on chemotherapy [21] without additional risk for complications. Reversal of temporary stomas can give rise to complications in about $32 \%$ of patients i.e. wound sepsis, small bowel obstruction and incisional hernia [18].

\section{Patient selection}

It is not necessary to mature a diverting stoma on every patient undergoing LAR. Only those who can outweigh the risk of complications and morbidity of a stoma to the benefits of having it, should be given a stoma [22, 23]. Following a retrospective and prospective review of articles spanning over 50yrs M. Hanna et al reported low colo-rectal anastomosis, colo-anal anastomosis, difficult resections, malnutrition and male patients would be benefitted by a diverting stoma [24, $25,26]$.

Pre-operative chemoradiation, low rectal anastomosis and male gender are predisposing for AL [27]. The proximal diverting stoma will reduce the incidence of $\mathrm{AL}$, the manifestations of AL and reduce the need for immediate reoperation rates $[3,24,25]$. However, evidence of proximal faecal diversion on the reduction of mortality is inconclusive [2]

Those patients with obstructing colorectal cancer resection and anastomosis with a proximal diverting ileostomy would have higher complication rates, deep wound infections, sepsis and readmission rates [28].

With contradicting opinions as above, it is challenging to decide who would benefit from a diverting stoma. We can safely conclude it would be beneficial to mature a diverting stoma in a male; whose anastomosis is located within $6 \mathrm{~cm}$ from the anal verge [25].

All authors disclose no conflict of interest. The study was conducted in accordance with the ethical standards of the relevant institutional or national ethics committee and the Helsinki Declaration of 1975, as revised in 2000 


\section{References}

1. Rahbari NN, Weitz J, Hohenberger W, et al. Definition and grading of anastomotic leakage following anterior resection of the rectum: A proposal by the International Study Group of Rectal Cancer. Surgery. 2010;147(3):339-351.

https://doi:10.1016/j.surg.2009.10.012

2. Tan WS, Tang CL, Shi L, Eu KW. Meta-analysis of defunctioning stomas in low anterior resection for rectal cancer. Br J Surg. 2009. https://doi:10.1002/bjs.6594

3. Wu S-W, Ma C-C, Yang Y. Role of protective stoma in low anterior resection for rectal cancer: A meta-analysis. World J Gastroenterol. 2014. https://doi:10.3748/wjg.v20.i47.18031

4. Wu Y, Zheng H, Guo T, Keranmu A, Liu F, Xu Y. Temporary Diverting Stoma Improves Recovery of Anastomotic Leakage after Anterior Resection for Rectal Cancer. Sci Rep. 2017;7(1). https://doi:10.1038/s41598-017-16311-7

5. Sun Z, Kim J, Adam MA, et al. Minimally invasive versus open low anterior resection equivalent survival in a national analysis of 14,033 patients with rectal cancer. Ann Surg. 2016. https://doi:10.1097/SLA.0000000000001388

6. Jeong SY, Park JW, Nam BH, et al. Open versus laparoscopic surgery for mid-rectal or low-rectal cancer after neoadjuvant chemoradiotherapy (COREAN trial): Survival outcomes of an open-label, non-inferiority, randomised controlled trial. Lancet Oncol. 2014;15(7).https:// doi:10.1016/S1470-2045(14)70205-0

7. Kang SB, Park JW, Jeong SY, et al. Open versus laparoscopic surgery for mid or low rectal cancer after neoadjuvant chemoradiotherapy (COREAN trial): Short-term outcomes of an open-label randomised controlled trial. Lancet Oncol. 2010;11(7):637-645. https://doi:10.1016/S1470-2045(10)70131-5

8. Ihnát $\mathrm{P}$, Guňková $\mathrm{P}$, Peteja $\mathrm{M}$, Vávra $\mathrm{P}$, Pelikán $\mathrm{A}$, Zonča $\mathrm{P}$. Diverting ileostomy in laparoscopic rectal cancer surgery: high price of protection. Surg Endosc Other Interv Tech. 2016. https://doi:10.1007/s00464-016-4811-3

9. Fasth S, Hultén L. Loop ileostomy: A superior diverting stoma in colorectal surgery. World J Surg. 1984. doi:10.1007/BF01655089

10.Guenaga KF, Silva Lustosa SA, Saad SS, Saconato H, Matos D. Ileostomy or colostomy for temporary decompression of colorectal anastomosis. Systematic review and meta-analysis. ACTACir Bras. 2008;23(3):294-303

https://doi:10.1590/S0102-86502008000300014

11.Edwards DP, Sexton R, Moran BJ. Randomized clinical trial comparing loop ileostomy and loop transverse colostomy for faecal diversion following total mesorectal excision ( Br J Surg 2002; 89: 704-8). Br J Surg. 2002;89(11):1480-1480. https://doi:10.1046/j.1365-2168.2002.02246_1.x

12. Kulu Y, Ulrich A, Bruckner T, et al. Validation of the International Study Group of Rectal Cancer definition and severity grading of anastomotic leakage. Surg (United States). 2013. https://doi:10.1016/j.surg.2013.02.007

13. Watanabe T, Miyata H, Konno H, et al. Prediction model for complications after low anterior resection based on data from 33,411 Japanese patients included in the National Clinical Database. Surg (United States). 2017;161(6):1597-1608. https://doi:10.1016/j.surg.2016.12.011

14.Rondelli F, Balzarotti R, Bugiantella W, Mariani L, Pugliese R,
Mariani E. Temporary percutaneous ileostomy versus conventional loop ileostomy in mechanical extraperitoneal colorectal anastomosis: A retrospective study. Eur J Surg Oncol. 2012. https://doi:10.1016/j.ejso.2012.07.110

15.Bugiantella W, Rondelli F, Mariani L, et al. Temporary percutaneous ileostomy for faecal diversion after intestinal resection for acute abdomen in elderly: How to avoid the conventional loop ileostomy. Int J Surg. 2014.

https://doi:10.1016/j.ijsu.2014.08.361

16. Cerroni M, Cirocchi R, Morelli U, et al. Ghost Ileostomy with or without abdominal parietal split. World J Surg Oncol. 2011. https://doi:10.1186/1477-7819-9-92

17.Miccini M, Bonapasta SA, Gregori M, Barillari P, Tocchi A. Ghost ileostomy: Real and potential advantages. Am J Surg. 2010. https://doi:10.1016/j.amjsurg.2009.12.017

18. Thoker M, Wani I, Parray FQ, Khan N, Mir SA, Thoker P. Role of diversion ileostomy in low rectal cancer: A randomized controlled trial. Int J Surg. 2014 https://doi:10.1016/j.ijsu.2014.07.012

19.Chiu A, Chan HT, Brown CJ, Raval MJ, Phang PT. Failing to reverse a diverting stoma after lower anterior resection of rectal cancer. Am J Surg. 2014.

https://doi:10.1016/j.amjsurg.2013.12.016

20.Zhu H, Bai B, Shan L, et al. Preoperative radiotherapy for patients with rectal cancer: a risk factor for non-reversal of ileostomy caused by stenosis or stiffness proximal to colorectal anastomosis. Oncotarget. 2017;8(59):100746-100753. https://doi:10.18632/oncotarget.20602

21.Kye BH, Kim HJ, Kim JG, Cho HM. Is it safe the reversal of a diverting stoma during adjuvant chemotherapy in elderly rectal cancer patients? Int J Surg. 2014.

https://doi:10.1016/j.ijsu.2014.10.018

22. Seo SI, Yu CS, Kim GS, et al. The role of diverting stoma after an ultra-low anterior resection for rectal cancer. Ann Coloproctol. 2013. https://doi:10.3393/ac.2013.29.2.66

23.Devaraj B, Cologne KG. Role of fecal diversion in colorectal anastomotic failure: Where are we now? Semin Colon Rectal Surg. 2014. https://doi:10.1053/j.scrs.2014.04.006

24.Hanna MH, Vinci A, Pigazzi A. Diverting ileostomy in colorectal surgery: when is it necessary? Langenbeck's Arch Surg. 2015. https://doi:10.1007/s00423-015-1275-1

25.Mrak K, Uranitsch S, Pedross F, et al. Diverting ileostomy versus no diversion after low anterior resection for rectal cancer: A prospective, randomized, multicenter trial.Surg (United States). 2016. https://doi:10.1016/j.surg.2015.11.006

26.Shiomi A, Ito M, Saito N, et al. The indications for a diverting stoma in low anterior resection for rectal cancer: A prospective multicentre study of 222 patients from Japanese cancer centers. Color Dis. 2011. https://doi:10.1111/j.1463-1318.2010.02481.x

27.Pommergaard HC, Gessler B, Burcharth J, Angenete E, Haglind E, Rosenberg J. Preoperative risk factors for anastomotic leakage after resection for colorectal cancer: A systematic review and meta-analysis. Color Dis. 2014. https://doi:10.1111/codi.12618

28.Shwaartz C, Fields AC, Prigoff JG, Aalberg JJ, Divino CM. Should patients With obstructing colorectal cancer have proximal diversion? Am J Surg. 2017.

https://doi:10.1016/j.amjsurg.2016.08.005 